\title{
Immobilization of defined laccase combinations for enhanced oxidation of phenolic contaminants
}

\author{
Erik M. Ammann • Christoph A. Gasser • \\ Gregor Hommes • Philippe F.-X. Corvini
}

Received: 22 March 2013 / Revised: 11 June 2013 / Accepted: 12 June 2013 / Published online: 29 June 2013

(C) Springer-Verlag Berlin Heidelberg 2013

\begin{abstract}
Immobilization is an important method to increase enzyme stability and allow enzyme reuse. One interesting application in the field of environmental biotechnology is the immobilization of laccase to eliminate phenolic contaminants via oxidation. Fumed silica nanoparticles have interesting potential as support material for laccase immobilization via sorption-assisted immobilization in the perspective of applications such as the elimination of micropollutants in aqueous phases. Based on these facts, the present work aimed to formulate laccase-nanoparticle conjugates with defined laccase combinations in order to obtain nanobiocatalysts, which are active over a broad range of $\mathrm{pH}$ values and possess a large substrate spectrum to suitably address pollution by multiple contaminants. A multi-enzymatic approach was investigated by immobilizing five different types of laccases originating from a Thielavia genus, Coriolopsis polyzona, Cerrena unicolor, Pleurotus ostreatus, and Trametes versicolor onto fumed silica nanoparticles, separately and in combinations. The laccases differed concerning their $\mathrm{pH}$ optima and substrate affinity. Exploiting their differences allowed the formulation of tailormade nanobiocatalysts. In particular, the production of a nanobiocatalyst could be achieved that retained a higher percentage of its relative activity over the tested $\mathrm{pH}$ range (37) compared to the dissolved or separately immobilized enzymes. Furthermore, a nanobiocatalyst could be formulated able to oxidize a broader substrate range than the dissolved or separately immobilized enzymes. Thereby, the
\end{abstract}

E. M. Ammann • C. A. Gasser $(\bowtie) \cdot$ G. Hommes • P. F.-X. Corvini Institute for Ecopreneurship, School of Life Sciences, University of Applied Sciences and Arts Northwestern Switzerland,

Gründenstrasse 40, Muttenz 4132, Switzerland

e-mail: christoph.gasser@fhnw.ch

P. F.-X. Corvini

State Key Laboratory of Pollution Control and Resource Reuse, School of the Environment, Nanjing University Xianlin Campu, Xianlin Avenue 163, Nanjing 210023, China potential of the nanobiocatalyst for application in biochemical oxidation applications such as the elimination of multiple target pollutants in biologically treated wastewater has been illustrated.

Keywords Laccase · Fumed silica nanoparticles · Immobilization · Phenolic micropollutant $\cdot$ Wastewater treatment $\cdot$ Tailor-made nanobiocatalysts

\section{Introduction}

The economy of biocatalytic processes can be improved by enzyme reuse and increase of enzyme stability by means of immobilization technologies. Implementing the capacity of enzyme retention or recovery in existing processes enables biocatalyst separation from products; thereby allowing continuous processes and preventing carry-through of biocatalysts to subsequent process steps (Polizzi et al. 2007).

Even if obvious advantages could be achieved by enzyme immobilization (Brady and Jordaan 2009), only approximately $20 \%$ of biocatalytic processes make use of immobilized enzymes (Straathof et al. 2002). Interesting new developments in enzyme immobilization and applications thereof have been recently reported, particularly in the field of environmental technologies (i.e., wastewater treatment, water purification, biomass conversion, resource recovery, depollution, etc.). Thus, novel concepts for biocatalytic depollution have been developed (Corvini and Shahgaldian 2010), addressing the need to improve conventional wastewater treatment plants regarding their ability to cope with emerging organic contaminants (EOC).

In recent decades, EOCs such as pharmaceuticals, personal care products, and other hormonally active chemicals are often detected in wastewater treatment plant effluents, in surface waters, and even in groundwater (Cirja et al. 2008; Kuster 
et al. 2008; Lapworth et al. 2012). Wastewater treatment technologies for the removal of EOCs are especially challenging because exhaustive removal is needed as these contaminants retain their adverse properties even at low concentrations. Initial concentrations are typically very low, and the remediation techniques should generally be applicable to a wide range of different chemical compounds possessing diverse physicochemical properties, thus making the treatment cost per unit mass prohibitively expensive (Klavarioti et al. 2009).

One promising approach to face the challenge of costefficient EOC removal consists of the use of immobilized biocatalysts, such as the four-copper containing metalloenzymes laccases (benzenediol: oxygen oxidoreductases, EC 1.10.3.2), which can oxidize and thereby transform phenolic or anthropogenic compounds into less toxic derivatives by one-electron abstraction reaction (Majeau et al. 2010). However, the use of free enzymes for wastewater treatment is still limited due to their instability over time caused by harsh conditions of the environment; inadequate $\mathrm{pH}$, temperature, chemical denaturants, or salt concentration (Majeau et al. 2010; Cabana et al. 2011). The improvement of enzyme performance, such as activity even at environmentally relevant concentrations, well below $\mathrm{K}_{\mathrm{M}}$ values and stability under application relevant conditions can be achieved by enzyme immobilization on solid surfaces, such as fumed silica nanoparticles (Hommes et al. 2012). Moreover, immobilization of the biocatalyst can reduce the enzyme loss and facilitate their use in continuous processes, such as bioreactors using membrane filtration technology to retain the immobilized enzymes (Sheldon 2007; Hu et al. 2009; Corvini and Shagaldian 2010; Hommes et al. 2012).

Presently, few data are available on the removal of EOC from treated wastewater by means of enzymatic systems in literature. Therefore, the main objectives of this study were to demonstrate the feasibility of combining defined enzyme combinations specially designed to eliminate several EOCs. In the present study, the removal of seven EOCs, i.e., carbamazepine (CBZ), diclofenac (DF), sulfamethoxazole (SMX), ibuprofen (IBU), gemfibrozil (GFZ), benzophenone-2 (BP-2), benzophenone-4 (BP-4), and bisphenol A (BPA) all occurring in effluents from wastewater treatment plants (Pal et al. 2010; Fent et al. 2010; Bertanza et al. 2011), have been addressed.

In general, laccases have a broad range regarding substrate specificity, but the latter can vary a lot depending on the chemical structure of the target substrates. Therefore, laccase combinations were immobilized on functionalized fumed silica nanoparticles (fsNP) in order to combine the beneficial characteristics of different laccases as nanobiocatalysts and to increase the efficiency of EOC removal.

\section{Material and methods}

\section{Origins of laccases}

Origin and characteristics of applied laccases are shown in Table 1. Laccases were precipitated with acetone (up to $80 \%$ $(\mathrm{v} / \mathrm{v})$; on ice; $1 \mathrm{~h})$ before application in order to remove possible impurities. Subsequently, they were centrifuged $\left(21,000 \times g ; 5 \mathrm{~min} ; 4{ }^{\circ} \mathrm{C}\right)$, whereupon the supernatant was discarded, and the precipitate was dissolved in the respective buffer or $\mathrm{NaCl}(0.9 \%(\mathrm{w} / \mathrm{v}))$ for experiments with the extracellular Flux Analyzer XF-96-2 (CFA 96) and XF-24-2 (CFA 24) (Seahorse Bioscience, USA) respectively.

\section{Immobilization procedure}

Surface modification of fsNP (surface area: $390 \pm 40 \mathrm{~m}^{2} \mathrm{~g}^{-1}$; aggregates of particles with an average size of $7 \mathrm{~nm}$ ) from Sigma-Aldrich (Switzerland) were performed according to Hommes et al. (2012). Based on previous results (Hommes et al. 2012), optimal protein load, i.e., the protein load at which virtually all enzyme molecules applied could be immobilized, was calculated to be approximately $0.07 \mathrm{mg}$ protein per milligram fsNP. Immobilization of single enzymes was conducted according to Hommes et al. (2012). Proteins were applied in amounts close to the optimal protein load and are summarized for each nanobiocatalyst formulation in Table 2.

Co-immobilization of two and simultaneous immobilization of five enzymes was conducted in similar fashion. The same weight of protein per laccase was applied, and it was assured that the total protein amount used corresponded to the optimal protein load. In case of co-immobilization of two enzymes, control experiments were conducted, immobilizing the respective enzymes separately. For each enzyme, the protein amount applied for the production of single enzyme-fsNP conjugate was equal to the protein amount of the corresponding enzyme applied for co-immobilization. In case of the simultaneous immobilization of five enzymes, four separate control experiments were conducted. The number of laccases to be immobilized was increased in each experiment from one to four. For each enzyme, the protein amount applied in control experiments was equal to the protein amount of the corresponding enzyme applied for the simultaneous immobilization of five enzymes.

\section{Assays}

Analytical isoelectric focusing was carried out using a Model 111 Mini IEF Cell (Bio-Rad) according to the instruction manual. Amersham calibration kits (low range $(\mathrm{pH} \mathrm{3-10)}$ and high range ( $\mathrm{pH} 5-10.5)$ ) for $\mathrm{p} I$ determinations (GE Healthcare) were used as $\mathrm{p} I$ marker proteins. Bio-Lyte ampholyte (3/10, 
Table 1 Characteristics of the dissolved laccases

\begin{tabular}{|c|c|c|c|c|}
\hline Laccase & $\begin{array}{l}\text { Specific activity } \\
{\left[\mathrm{U} \mathrm{mg}^{-1} \text { protein }\right]}\end{array}$ & $\begin{array}{l}\text { Molecular activity } \\
{\left[\mathrm{GU} \mathrm{mol}^{-1} \text { laccase }\right]}\end{array}$ & $\begin{array}{l}\text { Molecular Weight }{ }^{b} \\
{[\mathrm{kDa}]}\end{array}$ & $\begin{array}{l}\text { Isoelectric point } \mathrm{p} I \\
{[\mathrm{pH}]}\end{array}$ \\
\hline Genus Thielavia (GTL) & \multirow[t]{2}{*}{$14.2 \pm 0.3$} & \multirow[t]{2}{*}{$3.3 \pm 0.1$} & \multirow[t]{2}{*}{75.6} & \multirow[t]{2}{*}{$4.2-7.6$} \\
\hline AB Enzymes GmbH (Germa & & & & \\
\hline Coriolopsis polyzona (CPL) & \multirow[t]{2}{*}{$22.1 \pm 1.0$} & \multirow[t]{2}{*}{$26.0 \pm 0.6$} & \multirow[t]{2}{*}{59.8} & \multirow[t]{2}{*}{3.9} \\
\hline Wetlands Engineering (Belgi & & & & \\
\hline Cerrena unicolor (CUL) & \multirow[t]{2}{*}{$6.0 \pm 0.1$} & \multirow[t]{2}{*}{$7.2 \pm 0.6$} & \multirow[t]{2}{*}{58.1} & \multirow[t]{2}{*}{3.8} \\
\hline Wetlands Engineering (Belgi & & & & \\
\hline Pleurotus ostreatus (POL) & \multirow[t]{2}{*}{$7.9 \pm 0.1$} & \multirow[t]{2}{*}{$16.2 \pm 2.0$} & \multirow[t]{2}{*}{58.3} & \multirow[t]{2}{*}{$<3.0$} \\
\hline Sigma-Aldrich (Switzerland) & & & & \\
\hline Trametes versicolor (TVL) & \multirow[t]{2}{*}{$12.5 \pm 0.3$} & \multirow[t]{2}{*}{$20.4 \pm 0.9$} & \multirow[t]{2}{*}{61.6} & \multirow[t]{2}{*}{$<3.0$} \\
\hline Sigma-Aldrich (Switzerland) & & & & \\
\hline
\end{tabular}

${ }^{\text {a }}$ Molecular activity calculated based on the molecular weight and specific laccase activity $\left(\mathrm{U} \mathrm{mg}^{-1}\right.$ laccase) reported recently by Hommes et al. (2013)

${ }^{\mathrm{b}}$ Molecular weight as reported recently by Hommes et al. (2013)

$40 \%$ ) was used as carrier ampholyte for the $\mathrm{pH}$ gradient, and gels were stained with Coomassie brilliant blue R-250. The total protein content of laccase working solutions was quantified by the bicinchoninic acid assay (Smith et al. 1985). Bicinchoninic acid protein assay kits (Pierce ${ }^{\circledR}$, Thermo Scientific, Germany) were used, and assays were conducted according to the instruction manual.
Standard activity measurements by means of colorimetric assays were performed as described elsewhere (Zimmerman et al. 2011; Hommes et al. 2013). One unit (U) has been defined as the amount of laccase able to oxidize $1 \mu \mathrm{mol} 2,2^{\prime}$ Azino-bis (3-ethylbenzthiazoline)-6-sulphonic acid (ABTS) per minute at $\mathrm{pH} 3$ at $25{ }^{\circ} \mathrm{C}$. Furthermore, the activities of both free and immobilized laccases were determined by

Table 2 Comparison of different laccase-fsNP conjugates produced with different laccases and laccase mixtures $(n=3)$

\begin{tabular}{|c|c|c|c|c|}
\hline \multirow[t]{2}{*}{ Applied laccase(s) } & \multicolumn{2}{|c|}{ Washing Loss } & \multirow{2}{*}{$\begin{array}{l}\text { Immobilization Yield }^{\mathrm{c}} \\
{[\%]}\end{array}$} & \multirow{2}{*}{$\begin{array}{l}\text { Enzyme Load }^{\mathrm{d}} \\
{\left[\mathrm{U} \mathrm{mg}^{-1} \mathrm{fsNP}\right]}\end{array}$} \\
\hline & {$[\%]^{\mathrm{a}}$} & {$[\%]^{\mathrm{b}}$} & & \\
\hline GTL (0.056 mg protein $\left.\mathrm{mg}^{-1} \mathrm{fsNP}\right)$ & $4.8 \pm 3.9$ & $6.0 \pm 0.5$ & $126.1 \pm 9.6$ & $0.91 \pm 0.05$ \\
\hline CPL (0.088 mg protein $\left.\mathrm{mg}^{-1} \mathrm{fsNP}\right)$ & $17.1 \pm 1.8$ & $15.2 \pm 0.5$ & $139.3 \pm 9.5$ & $2.42 \pm 0.12$ \\
\hline CUL (0.080 mg protein $\left.\mathrm{mg}^{-1} \mathrm{fsNP}\right)$ & $17.6 \pm 6.5$ & $18.0 \pm 0.8$ & $161.3 \pm 17.3$ & $0.70 \pm 0.07$ \\
\hline POL (0.062 mg protein $\left.\mathrm{mg}^{-1} \mathrm{fsNP}\right)$ & $2.1 \pm 3.1$ & $8.5 \pm 1.3$ & $228.3 \pm 16.4$ & $1.05 \pm 0.06$ \\
\hline TVL $\left(0.050 \mathrm{mg}\right.$ protein $\left.\mathrm{mg}^{-1} \mathrm{fsNP}\right)$ & $7.2 \pm 1.8$ & $2.9 \pm 0.1$ & $191.1 \pm 8.9$ & $1.08 \pm 0.02$ \\
\hline GTL $\left(0.014 \mathrm{mg}\right.$ protein $\left.\mathrm{mg}^{-1} \mathrm{fsNP}\right)$ & $7.4 \pm 4.5$ & $0.5 \pm 0.0$ & $180.0 \pm 8.7$ & $0.30 \pm 0.01$ \\
\hline GTL, CPL (0.028 mg protein $\mathrm{mg}^{-1}$ fsNP) & $6.7 \pm 2.7$ & $0.5 \pm 0.0$ & $205.4 \pm 15.4$ & $0.78 \pm 0.06$ \\
\hline GTL, CPL, and CUL (0.042 mg protein $\mathrm{mg}^{-1}$ fsNP) & $5.5 \pm 2.1$ & $0.5 \pm 0.0$ & $204.7 \pm 3.4$ & $0.86 \pm 0.04$ \\
\hline GTL, CPL, and CUL, POL (0.056 mg protein $\left.\mathrm{mg}^{-1} \mathrm{fsNP}\right)$ & $9.1 \pm 0.5$ & $2.6 \pm 0.1$ & $201.9 \pm 13.1$ & $1.01 \pm 0.02$ \\
\hline GTL, CPL, CUL, POL, and TVL (0.070 mg protein $\mathrm{mg}^{-1} \mathrm{fsNP}$ ) & $11.8 \pm 3.3$ & $5.0 \pm 0.3$ & $190.7 \pm 1.8$ & $1.10 \pm 0.03$ \\
\hline GTL (0.035 mg protein $\mathrm{mg}^{-1}$ fsNP) & $5.7 \pm 0.6$ & $4.3 \pm 0.3$ & $166.1 \pm 3.1$ & $0.69 \pm 0.00$ \\
\hline POL (0.035 mg protein $\left.\mathrm{mg}^{-1} \mathrm{fsNP}\right)$ & $5.1 \pm 3.5$ & $3.4 \pm 0.3$ & $227.4 \pm 3.8$ & $0.55 \pm 0.02$ \\
\hline GTL and POL (total $0.070 \mathrm{mg}$ protein $\mathrm{mg}^{-1}$ fsNP) & $10.0 \pm 2.9$ & $9.8 \pm 0.8$ & $155.7 \pm 1.7$ & $1.03 \pm 0.02$ \\
\hline CPL (0.035 mg protein $\mathrm{mg}^{-1}$ fsNP) & $8.5 \pm 3.1$ & $0.5 \pm 0.0$ & $194.4 \pm 6.8$ & $0.93 \pm 0.02$ \\
\hline TVL $\left(0.035 \mathrm{mg}\right.$ protein $\left.\mathrm{mg}^{-1} \mathrm{fsNP}\right)$ & $9.7 \pm 2.2$ & $2.3 \pm 0.2$ & $212.0 \pm 4.7$ & $0.75 \pm 0.04$ \\
\hline CPL and TVL (total $0.070 \mathrm{mg}$ protein $\mathrm{mg}^{-1} \mathrm{fsNP}$ ) & $9.7 \pm 4.0$ & $6.4 \pm 0.1$ & $184.0 \pm 5.6$ & $1.37 \pm 0.03$ \\
\hline
\end{tabular}

Washing loss was determined in two different ways, i.e., as ${ }^{\text {a }}$ relative difference between the apparent (measured) laccase activity bound to the fsNP after exhaustive washing and the apparent laccase activity before washing $(100 \%)$ and ${ }^{\mathrm{b}}$ apparent laccase activity discarded during washing relative to the apparent laccase activity before washing $(100 \%)$, i.e., the relative laccase activity discarded during washing

${ }^{\mathrm{c}}$ Immobilization yield was defined as apparent laccase activity of the completed nanobiocatalyst suspensions relative to the initially applied laccase activity $(100 \%)$

${ }^{\mathrm{d}}$ Enzyme load was defined as apparent laccase activity per mg fsNP of the completed nanobiocatalysts 
oxygen consumption rate (OCR) measurements using a novel assay based on fluorimetric sensors in a multiwell plate format using the CFA 24 and CFA 96 as recently described (Hommes et al. 2013). All OCR measurements were performed in Mcllvaine phosphate-citrate buffer (McIlvaine 1921). The method for determination of laccase activities towards target substances differed between immobilized and dissolved enzymes.

In case of dissolved enzymes, laccase was injected through the injection ports in order to start the enzymatic reaction. OCR measurements with dissolved laccases and target substances were conducted using the CFA 24. All additional experiments were performed with the CFA 96 in order to increase throughput. Substrate concentrations were usually $1 \mathrm{mM}$, except for 2, 6-dimethoxyphenol (2, 6-DMP), for which concentrations were $2 \mathrm{mM}$.

Applied enzymatic activities of dissolved laccases were varied depending on laccase origin, substrate, and $\mathrm{pH}$ and were between 200 and 13,000 $\mathrm{U} \mathrm{L}^{-1}$ for the reference phenolic substrates, i.e., 2, 6-DMP and hydroquinone (HQ) and between 3,000 and 40,000 $\mathrm{U} \mathrm{L}^{-1}$ for the target substances. OCR were calculated using the "Level (direct) Akos" algorithm that is part of the Seahorse CFA software package. The algorithm accounts for $\mathrm{O}_{2}$ flux into the measurement volume through the walls of the microplate and the atmosphere and has been described before (Gerencser et al. 2009).

All experiments with immobilized laccases were conducted using the CFA 96. Contrary to the experiments using dissolved laccases, substrates were injected through the injection ports in order to start the enzymatic reaction because immobilized enzymes would have clogged the injection ports. For BP-2 and 2, 6-DMP, initial stock concentration was adjusted in order to reach a well concentration of 1 and $2 \mathrm{mM}$ after injection, respectively. All other substances were applied at their solubility limit, and final well volume was reduced from 200 to $180 \mu \mathrm{L}$ in order to reach substance concentrations as high as possible inside the wells.

Applied enzymatic activities of immobilized laccases for oxidation of the reference phenolic substrate 2, 6-DMP varied depending on laccase origin, substrate, and $\mathrm{pH}$ and were between 50 and 2,100 $\mathrm{U} \mathrm{L}^{-1}$. OCRs were calculated as for dissolved laccases.

Applied enzymatic activities of immobilized laccases for the oxidation of target substances at $\mathrm{pH} 7$ varied depending on laccase origin and substrate and were between 1,000 and $42,000 \mathrm{U} \mathrm{L}^{-1}$, corresponding to fsNP concentrations between 1 and $30 \mathrm{~g} \mathrm{~L}^{-1}$.

Decrease in $\mathrm{O}_{2}$ concentration after substrate injection was calculated by linear regression of the measured $\mathrm{O}_{2}$ concentrations. In order to evaluate if significant $\mathrm{O}_{2}$ consumption occurred, $\mathrm{O}_{2}$ decreases in the samples were compared to $\mathrm{O}_{2}$ decreases in controls containing immobilized enzymes, where only buffer and no substrate was injected by using analysis of variances (ANOVA). Prior to ANOVA, the dataset was tested on its normal distribution (Shapiro-Wilk normality test, chosen significance level $p<0.1)$ and equal variances (Bartlett test of homogeneity of variances, chosen significance level $p<0.1$ ), respectively.

Stability assays to compare the stability of the immobilized and dissolved enzymes were conducted in filtered $(11 \mu \mathrm{m}$ cutoff, grade 1, Whatman, Germany) wastewater effluent ( $\mathrm{pH} 8.3$, COD $24.8 \mathrm{mg} \mathrm{L}^{-1}$ ) from wastewater treatment plant Birsfelden, Switzerland, as described elsewhere (Zimmermann et al. 2011), with slight modifications. Initial applied enzymatic activity usually was $10,000 \mathrm{U} \mathrm{L}^{-1}$ in total, except for laccase combinations, and co-immobilized laccases initial activity was $1,000 \mathrm{U} \mathrm{L}^{-1}$. In order to study the influence of initial laccase activity on stability, experiments with Coriolopsis polyzona (CPL) immobilized on fSNP (CPL-fSNP) were conducted with $1,000 \mathrm{U} \mathrm{L}^{-1}$ as well as with $10,000 \mathrm{U} \mathrm{L}^{-1}$.

\section{Results}

Laccases were tested regarding their suitability for immobilization, their activity over a broad range of $\mathrm{pH}$ values, and their ability to transform selected pollutants. Furthermore, a strategy to design defined multi-enzymatic nanobiocatalyst for environmental applications has been investigated.

Immobilization of laccases and laccase combinations

In the present paper, five laccases of different origin have been successfully immobilized on surface-modified fumed silica nanoparticles as summarized in Table 2.

\section{Coupling of single laccases}

Losses of enzymatic activity during washing steps of the immobilization procedure (washing losses) of single laccases were below $10 \%$ for genus Thielavia (GTL), Pleurotus ostreatus (POL), and Trametes versicolor (TVL), indicating that these biocatalysts were almost entirely immobilized on the support material. For CPL and Cerrena unicolor (CUL), washing losses were higher compared to the other three enzymes but still below $20 \%$. The slightly higher washing losses for CPL and CUL were most likely due to the fact that the protein loads $(0.088$ and $0.080 \mathrm{mg}$ protein per milligram fsNP, respectively) actually used were slightly above the calculated optimal protein load $(0.07 \mathrm{mg}$ protein per milligram fsNP) for these two enzymes. The specific activities of the enzyme suspensions correlated nicely with the enzyme loads of the corresponding nanobiocatalysts, i.e., higher specific activities of the enzyme suspensions resulted in higher enzyme loads of the nanobiocatalysts. Particularly for CPL, the 
enzyme load was quite high $\left(2.42 \pm 0.12 \mathrm{U} \mathrm{mg}^{-1} \mathrm{fsNP}\right)$ in comparison to the other nanobiocatalysts.

\section{Coupling of multiple laccases}

In order to test whether immobilization of all five investigated laccases onto the same particles was feasible, different experiments were conducted. The number of laccases to be immobilized was increased successively from one up to five. With each increase in the number of applied laccases, the resulting nanobiocatalysts showed an increase in total enzyme load. Herewith, it could be shown that all five laccases were successfully co-immobilized, and thereby a biocatalyst containing all five laccases (multi-fsNP) could be produced. Therefore, the suitability of the applied method to immobilize defined combinations of laccases was proven. This allowed selection of laccase combinations for immobilization on the same particle based on their capabilities in order to produce nanobiocatalysts with enhanced abilities compared to the single enzymes. Two pairs of laccases were selected for coimmobilization, i.e., CPL and TVL as well as GTL and POL. CPL and TVL were selected for co-immobilization onto the same particles, in order to produce nanobiocatalysts able to transform a broader range of compounds than single-enzyme nanoparticle conjugates. GTL and POL were chosen for coimmobilization in order to produce nanobiocatalysts that retain most of their maximal enzymatic activity over a broader $\mathrm{pH}$ range.

Co-immobilizations of two laccases were assessed similar to the immobilization of five laccases by running control experiments applying only one laccase. Enzyme load of both two-enzyme nanobiocatalysts, i.e., CPL and TVL coimmobilized on fsNP (CPL-TVL-fsNP) as well as for GTL and POL co-immobilized on fsNP (GTL-POL-fsNP), was higher after immobilization of both laccases compared to experiments where only one laccase was immobilized, indicating successful immobilization.

Stability of laccases and nanobiocatalysts thereof in conventionally treated wastewater

Long-term stability assays in conventionally treated wastewater showed a considerable stabilization of the enzymatic activity of the immobilized compared to the free enzymes. Immobilized laccases retained activity over the whole measurement period of 40 days, while soluble forms of CPL, POL, and TVL lost virtually all activity within 9 days, and CUL and GTL lost virtually all activity within 23 days. However, the stability of the single-laccase conjugates differed considerably depending on the laccase. Between $19.7 \pm 2.3$ (GTL-fsNP) and $72.4 \pm 2.0 \%$ (CUL-fsNP) of the initial enzymatic activity $\left(10,000 \mathrm{U} \mathrm{L}^{-1}\right)$ remained after 40 days. Stability of the enzymatic activity of the conjugates depended on the initially applied enzymatic activity, as experiments conducted with CPL-fsNP applying two different initial enzymatic activities, i.e., 1,000 and $10,000 \mathrm{U} \mathrm{L}^{-1}$ showed. After 40 days of incubation, enzymatic activity decreased to $15.7 \pm 2.3$ and $49.7 \pm 2.9 \%$ for the experiment applying 1,000 and 10,000 U L ${ }^{-1}$, respectively. Enzymatic activity of the double- and multi-fsNP conjugates remained at $17.8 \pm 0.4,39.1 \pm 1.1$, and $27.1 \pm 4.0 \%$ for GTL-POLfsNP, CPL-TVL-fsNP, and multi-fsNP conjugates, respectively, after 40 days of incubation and initial enzymatic activity of $1,000 \mathrm{U} \mathrm{L}^{-1}$.

Substrate oxidation by dissolved and immobilized laccases

The ability of free laccases to oxidize selected organic contaminants in buffer solutions was investigated over a $\mathrm{pH}$ range of 3-7 by means of oxygen consumption measurements. For benchmarking 2, 6-DMP, a standard substrate to determine laccase activity was used.

\section{Oxidation activity—benchmarking using standard substrate}

Figure 1 shows the normalized activity of the different laccases (A) and immobilized laccases (B) at different $\mathrm{pH}$ values in the presence of 2, 6-DMP. All laccases reached their maximal activity at $\mathrm{pH} 4$ with the exception of GTL, which reached its maximal activity at $\mathrm{pH} 5$. Laccase activity was reduced below $20 \%$ of the maximal activity at $\mathrm{pH} 6$ for CUL, POL, and TVL. At $\mathrm{pH} 7$, the measured activity for these three laccases was below the limit of detection. For $\mathrm{CPL}$, the reduction in laccase activity at higher $\mathrm{pH}$ values was not as drastic and remained at approximately 31 and $16 \%$ of the maximal activity at $\mathrm{pH} 6$ and 7 , respectively. GTL retained $80 \%$ of its maximal activity at $\mathrm{pH} 6$, and at $\mathrm{pH} 7,50 \%$ of the maximal activity remained.

For all investigated laccases, the immobilization of the enzymes did not lead to an observable shift of the optimal $\mathrm{pH}$ regarding enzymatic activity. However, immobilized enzymes retained a higher percentage of their maximal activity compared to free enzymes at pH 6 and 7. Especially, GTLfsNP showed little losses in activity at higher $\mathrm{pH}$ values compared to other immobilized laccases, retaining 97 and $74 \%$ of maximal enzymatic activity at pH 6 and 7, respectively. At pH 3, losses in enzymatic activity compared to the maximal enzymatic activity were also smaller for all enzymes after immobilization, except for GTL. Notably, TVL retained most of its maximal enzymatic activity after immobilization at $\mathrm{pH} 3$, i.e., $88 \%$, while it only retained $28 \%$ in its dissolved form.

The co-immobilization of GTL and POL led to the anticipated extension of the $\mathrm{pH}$ range, in which the nanobiocatalysts retained enzymatic activity. Enzymatic activities were always above $70 \%$ of the activity maximum of the GTL-POL-fsNP 


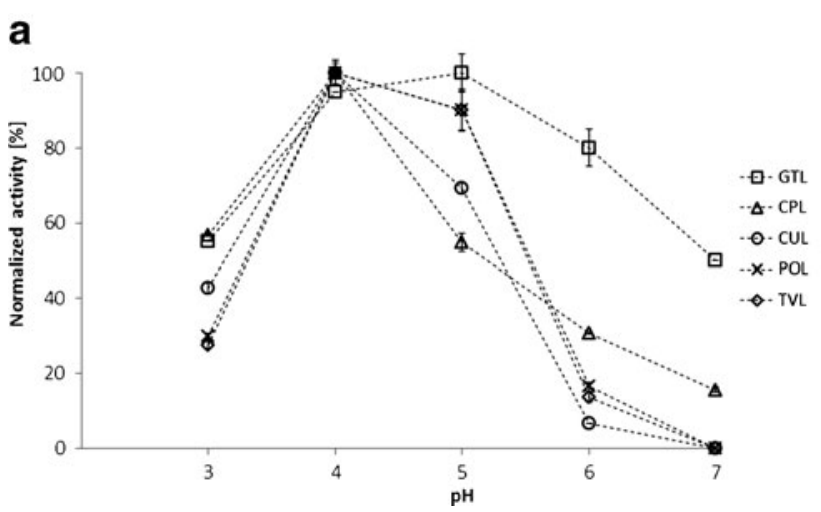

Fig. 1 Enzymatic activity of laccases (a) and immobilized laccases (b) at different $\mathrm{pH}$ values during the oxidation of 2, 6-DMP $(2 \mathrm{mM})$. a Single laccase in its soluble form from genus Thielavia laccase (GTL), Coriolopsis polyzona (CPL), Cerrena unicolor (CUL), Pleurotus ostreatus (POL), and Trametes versicolor (TVL). b Single laccase-fsNP conjugates from genus Thielavia laccase $\left(G T L-f_{S} N P\right)$, Coriolopsis polyzona $\left(C P L-f_{S} N P\right)$,

over the tested $\mathrm{pH}$ range from 3 to 7 . This constitutes a clear improvement at $\mathrm{pH}$ values above 4 compared to the nanobiocatalyst, in which POL was used as a sole enzyme and at $\mathrm{pH} 3$ compared to the one-enzyme nanobiocatalyst, in which GTL was used.

Furthermore, an increase in enzymatic activity towards the substrate ABTS at $\mathrm{pH} 3$ was observed for all laccase genera after immobilization, as is apparent by the immobilization yields above $100 \%$ that were achieved for all laccases and laccase combinations (Table 2). Enzymatic activity after immobilization also increased, when 2, 6-DMP was used as a substrate for all laccases at all $\mathrm{pH}$ values investigated. Oneenzyme nanobiocatalysts showed increased enzymatic activity towards 2, 6-DMP between 3.5- (pH 5, TVL-fsNP) and 9.4fold $(\mathrm{pH}$ 6, TVL-fsNP) compared to the corresponding dissolved enzymes. Enzymatic activity towards 2, 6-DMP by co-immobilized enzymes increased between 4.9- ( $\mathrm{pH} 4$, GTLPOL-fsNP) and 11.6-fold (pH 7, GTL-POL-fsNP) compared to the corresponding mixture of dissolved enzymes at the same enzyme ratio. Immobilization of five different laccases onto one carrier led to an increase in enzymatic activity towards 2 , 6-DMP between 10.3- (pH 3) and 15.5-fold (pH 7), in comparison to a mixture of the respective native laccases applied at the same enzyme ratio.

\section{Oxidation of target compounds}

Table 3 summarizes the results from the screening of the five laccases regarding their ability to oxidize different potential target compounds. No noticeable OCRs were measured with compounds SMX, CBZ, or IBU irrespective of the laccase used, indicating that these substrates are not or only slowly transformed by the studied enzymes.

HQ and BPA could be transformed by all laccases, while experiments with DF showed relevant OCRs for all laccases

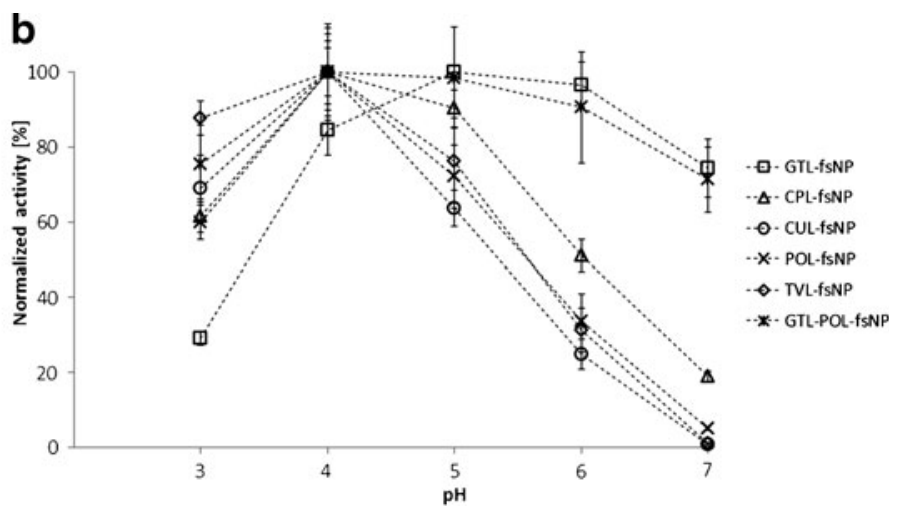

Cerrena unicolor (CUL-fSNP), Pleurotus ostreatus $\left(P O L-f_{S} N P\right)$, and Trametes versicolor $\left(T V L-f_{s} N P\right)$ and two laccase-fsNP conjugates from GTL and POL $\left(G T L-P O L-f_{S} N P\right)$. Laccase activity is normalized to the highest measured activity of the corresponding enzyme, error bars show the standard deviations $(n=5)$

except CUL. GFZ, BP-2, and BP-4 seemed to be less prone to oxidation by laccases, since no remarkable OCRs were observed for three (in case of BP-2 and BP-4) or even four (in case of GFZ) of the tested laccases. Notable OCRs for GFZ were only measured with CPL; for BP-2, OCRs above LOD were detected in the presence of TVL and CUL, and for BP-4, noteworthy OCRs could be measured in the presence of TVL and CPL.

Regarding the $\mathrm{pH}$ activity profiles of the laccases concerning the oxidation of the selected target contaminants, it is clear that the $\mathrm{pH}$ activity optimum of the respective laccase is substrate dependent. CPL for example showed highest enzymatic activity at $\mathrm{pH} \mathrm{4,5}$, and 6 for 2, 6-DMP, HQ, and DF, respectively. Crude GTL was the only laccase showing high oxidation activity at neutral $\mathrm{pH}$ towards BPA and DF, indicating that the application of GTL in wastewater treatment is suitable, since domestic wastewater is usually neutral to alkaline ( $\mathrm{pH}$ 7-9).

Apart from the compounds that are not transformed by all laccases, GFZ was the only compound that was not oxidized by TVL. Since CPL was the only laccase that measurably reduced oxygen concentration in the presence of GFZ, CPL and TVL were co-immobilized on fsNP in order to produce a nanobiocatalyst able to oxidize all five EOCs prone to oxidation by laccase. Oxidation of target substances with CPLTVL-fsNP led only to considerable decreases in $\mathrm{O}_{2}$ concentration, when particle concentrations were $1 \mathrm{~g} \mathrm{~L}^{-1}$ or higher. Since preliminary experiments have shown that $\mathrm{O}_{2}$ flux into the measurement volume is measurably influenced by fsNP concentrations above $\sim 1 \mathrm{~g} \mathrm{~L}^{-1}$, OCR calculations using the "Level (direct) Akos" algorithm were not suitable for the experiments using CPL-TVL-fsNPs for the oxidation of target substances. Therefore, observed linear decreases in $\mathrm{O}_{2}$ concentration were quantified by linear regression. Decreases in $\mathrm{O}_{2}$ concentrations were $3.78 \pm 0.48,0.74 \pm 0.14,0.80 \pm 0.08,1.86 \pm 0.30$, and $0.49 \pm 0.08 \mathrm{mmHg} \mathrm{min}^{-1}$ for BPA, DF, GFZ, BP-2, and BP-4, 
Table 3 Measured initial OCRs during treatment of different potential target compounds with dissolved laccases. Target compounds were applied with an initial concentration of $1 \mathrm{mM}$

\begin{tabular}{|c|c|c|c|c|c|c|}
\hline \multirow[t]{2}{*}{ Compound } & \multirow[t]{2}{*}{ Laccase } & \multicolumn{5}{|c|}{ OCR $\left[\mu \mathrm{mol} \mathrm{min}^{-1} \mathrm{mg}^{-1}\right.$ laccase $]$} \\
\hline & & pH 3 & $\mathrm{pH} 4$ & pH 5 & $\mathrm{pH} 6$ & pH 7 \\
\hline \multirow[t]{5}{*}{ Hydroquinone (HQ) } & Genus Thielavia & $<$ LOD & $<\mathrm{LOD}$ & $2.30 \pm 0.43$ & $5.68 \pm 0.37$ & $4.45 \pm 0.34$ \\
\hline & Coriolopsis polyzona & $9.56 \pm 1.58$ & $43.51 \pm 7.42$ & $70.00 \pm 7.70$ & $40.22 \pm 4.04$ & $9.09 \pm 0.50$ \\
\hline & Cerrena unicolor & $<0.69$ & $2.75 \pm 0.30$ & $12.80 \pm 1.73$ & $3.61 \pm 0.79$ & $<0.22$ \\
\hline & Pleurotus ostreatus & $3.28 \pm 0.45$ & $27.15 \pm 1.68$ & $55.59 \pm 13.72$ & $22.62 \pm 2.73$ & $3.53 \pm 0.21$ \\
\hline & Trametes versicolor & $1.41 \pm 0.38$ & $8.92 \pm 2.53$ & $41.24 \pm 6.97$ & $15.30 \pm 4.11$ & $<0.66$ \\
\hline \multirow[t]{5}{*}{ Bisphenol A (BPA) } & Genus Thielavia & $<\mathrm{LOD}$ & $<\mathrm{LOD}$ & $<0.12$ & $0.14 \pm 0.04$ & $0.23 \pm 0.03$ \\
\hline & Coriolopsis polyzona & $<0.95$ & $<0.95$ & $1.48 \pm 0.08$ & $1.53 \pm 0.17$ & $<0.95$ \\
\hline & Cerrena unicolor & $<0.43$ & $<0.76$ & $<0.76$ & $0.85 \pm 0.15$ & $<\mathrm{LOD}$ \\
\hline & Pleurotus ostreatus & $<\mathrm{LOD}$ & $<\mathrm{LOD}$ & $<1.27$ & $<1.27$ & $<\mathrm{LOD}$ \\
\hline & Trametes versicolor & $<\mathrm{LOD}$ & $<0.33$ & $<0.66$ & $<0.66$ & $<0.34$ \\
\hline \multirow[t]{4}{*}{ Diclofenac (DF) } & Genus Thielavia & - & - & $<\mathrm{LOD}$ & $<\mathrm{LOD}$ & $<0.09$ \\
\hline & Coriolopsis polyzona & - & - & $0.44 \pm 0.05$ & $0.63 \pm 0.08$ & $0.38 \pm 0.06$ \\
\hline & Pleurotus ostreatus & - & - & $<\mathrm{LOD}$ & $<0.33$ & $<\mathrm{LOD}$ \\
\hline & Trametes versicolor & - & - & $<0.14$ & $0.35 \pm 0.04$ & $0.23 \pm 0.02$ \\
\hline Gemfibrozil (GFZ) & Coriolopsis polyzona & $<0.42$ & $<0.42$ & $1.04 \pm 0.05$ & $0.78 \pm 0.10$ & $0.49 \pm 0.06$ \\
\hline \multirow[t]{2}{*}{ Benzophenone-2 (BP-2) } & Cerrena unicolor & $<\mathrm{LOD}$ & $<0.11$ & $<0.11$ & $0.17 \pm 0.03$ & $<0.11$ \\
\hline & Trametes versicolor & $<\mathrm{LOD}$ & $<0.28$ & $0.50 \pm 0.18$ & $0.98 \pm 0.11$ & $0.29 \pm 0.02$ \\
\hline \multirow[t]{2}{*}{ Benzophenone-4 (BP-4) } & Coriolopsis polyzona & $<0.10$ & $<0.10$ & $0.16 \pm 0.04$ & $0.09 \pm 0.03$ & $0.11 \pm 0.02$ \\
\hline & Trametes versicolor & $<\mathrm{LOD}$ & $<0.20$ & $0.22 \pm 0.02$ & $0.32 \pm 0.04$ & $0.25 \pm 0.03$ \\
\hline
\end{tabular}

Note that all laccases were tested at all $\mathrm{pH}$ values for all compounds. When for a particular laccase, no noteworthy enzymatic activity towards a defined compound was observed at all tested $\mathrm{pH}$ values, results corresponding to this laccase were omitted in this table

Less than sign $(<)$ oxygen consumption could be detected but was below the limit of quantification $(L O Q)$. The value given corresponds to the LOQ of the respective experiment, $<$ LOD no oxygen consumption rate above the limit of detection $(L O D)$ was measured under the applied conditions, en dash (-) solubility of target compound below $1 \mathrm{mM}$ at applied $\mathrm{pH}$ conditions

respectively, while they were $-1.27 \pm 0.59,0.00 \pm 0.11,0.25 \pm$

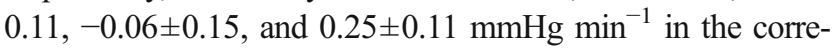
sponding controls only containing the same CPL-TVL-fsNP concentration and no substrate. ANOVA results for BPA, DF, GFZ, BP-2, and BP-4 ( $p$ values were $5.3 \times 10^{-7}, 2.1 \times 10^{-7}$, $1.5 \times 10^{-7}, 6.5 \times 10^{-9}$, and $7.0 \times 10^{-4}$, respectively) using CPLTVL-fsNP as biocatalyst showed that the measured $\mathrm{O}_{2}$ decreases in the samples containing one of the target substrates were significantly higher compared to $\mathrm{O}_{2}$ decreases in respective substrate-free controls. This suggests that the resulting nanobiocatalyst was able to oxidize GFZ, a compound that was not oxidized by TVL alone, as well as BP-2, a compound that was not oxidized by CPL alone, indicating that the goal of producing a nanobiocatalyst with a broader range of substrates compared to the one-laccase nanobiocatalysts could be achieved.

\section{Discussion}

Immobilizing different laccases on solid surfaces for industrial applications is of increasing interest. During the last years, laccases were immobilized successfully on several different support materials, e.g., magnetically separable mesoporous silica spheres (Zhu et al. 2007), nanoporous gold particles (Qiu et al. 2009), mesostructured cellular foams (Rekuć et al. 2009), and fumed silica nanoparticles (Zimmermann et al. 2011). In the present study, a previously developed and optimized immobilization strategy (Zimmermann et al. 2011; Hommes et al. 2012) has been applied for the successful immobilization of different laccases and combinations thereof. Furthermore, some possibilities to enhance the properties of nanobiocatalysts by immobilizing defined laccase combinations have been explored, and the enzymatic activity of the different laccases towards several EOCs at different $\mathrm{pH}$ values has been determined.

Immobilization — coupling of single catalyst

Successful immobilization of all single enzymes tested in this study could be demonstrated and led to nanobiocatalysts harboring between $0.70 \pm 0.07$ and $2.42 \pm 0.12 \mathrm{U}$ laccase activity per milligram fsNP depending on the laccase used. The resulting enzyme loads correlated with the specific activity 
of the applied laccases, and the resulting washing losses correlated with the applied protein amounts, indicating that similar protein amounts were immobilized per milligram fsNP irrespective of the enzyme used. This is in accordance with our previous studies (Zimmermann et al. 2011; Hommes et al. 2012), where we found that for CPL and GTL, relative washing losses were similar for similar protein amounts used irrespective of the enzyme and increased with increasing applied protein amounts.

Immobilized enzymes retained a higher percentage of their maximal enzymatic activity towards 2, 6-DMP compared to free enzymes over the tested $\mathrm{pH}$ range (except for GTL at $\mathrm{pH} 3$ ), indicating that the enzymatic activity is enhanced due to immobilization even at unfavorable $\mathrm{pH}$. Similar favorable effects of immobilization of laccases on the relative enzymatic activity at different $\mathrm{pH}$ values have been reported before (e.g., Yang et al. 2006). A shift of the optimum $\mathrm{pH}$ due to immobilization could not be observed for any of the laccases. However, since enzymatic activities were determined at discrete $\mathrm{pH}$ values, small shifts of the $\mathrm{pH}$ optimum, as reported for the immobilization of CUL (Luterek et al. 1998), might have not been detected.

Regarding the stability of the resulting biocatalysts in conventionally treated wastewater, the enzymes remain active over considerably longer time periods, if they are immobilized, and these results of the present study are in accordance with our previous findings (Zimmermann et al. 2011; Hommes et al. 2012). Stability increases due to immobilization on solid surfaces are mainly due to a reduction in the number of points of attack for proteases, an increase in the conformational stability due to the covalent binding, leading to a decreased possibility of unfavorable enzyme folding, and increased stability against harsh pH (Brady and Jordaan 2009; Rekuć et al. 2010; Zimmermann et al. 2011). Enzymatic activity decreased slower in experiments where higher initial enzymatic activities were used. This might be due to the presence of wastewater components that can act as enzyme inhibitors. A higher initial enzymatic activity means lower specific inhibitor concentrations (gram inhibitor per gram laccase). This might explain why inhibition of the enzymes progresses slower if initial activity is higher.

Immobilization—multi-catalyst approach

Successful co-immobilization of the studied laccases on the same particles could be demonstrated by successive immobilization of the five different enzymes. Furthermore, the coimmobilization of specifically selected laccases allowed the production of biocatalysts with a broader $\mathrm{pH}$-activity range, in case of the GTL-POL-fsNP, and with a broader substrate range, in case of the CPL-TVL-fsNP, compared to the corresponding singly immobilized laccases. This indicates that the characteristics of single laccases regarding $\mathrm{pH}$ activity profile and substrate specificity complemented one another after coimmobilization.

The amounts of enzyme that were immobilized on the fsNP were calculated based on the assumption that crosslinking with glutaraldehyde is in general nonspecific towards different proteins and consequently towards different enzymes, since cross-linking of proteins to a carrier with glutaraldehyde usually involves non-protonated $\varepsilon$-amino groups of lysin residues (Weetall 1974), and proteins usually exhibit many lysine residues on their surface, due to the polarity of the amine group (Migneault et al. 2004).

The experiments demonstrated that applying enzyme mixtures with total protein amounts equal or slightly below the protein amount that can be immobilized on the fsNP allows immobilizing defined combinations of enzymes. Whereas various laccases were immobilized in the present study, this method should be applicable to any combination of different classes of enzymes. The only issue to clarify would be whether the designated enzymes retain or lose their activity due to immobilization.

\section{Oxidation of EOCs}

\section{Oxidation activity - benchmarking using standard substrates}

An increase in enzymatic activity could be observed for all tested laccases towards the standard substrates ABTS and 2, 6-DMP after immobilization, indicating that the active sites of the enzymes were more readily accessible for these substrates due to conformational changes induced by immobilization, or that substrate concentrations near the particle surface were higher than in bulk solution due to interactions of the particle with the substrate. This is in accordance with our previous work, where immobilization as well as cross-linking with glutaraldehyde of GTL led to an increase in enzymatic activity towards ABTS (Hommes et al. 2012). Increased enzymatic activities due to cross-linking of laccases (Durán et al. 2002) and increased enzymatic activities towards 2, 6-DMP by approximately 10-fold due to encapsulation of laccase in sol-gel silica (Mohidem and Mat 2009) were reported before. Although, immobilization led to increased enzymatic activities towards the standard substrates for all five studied laccases, it has to be pointed out that this is not always valid. In a previous study, we found that enzymatic activity towards ABTS for laccase of Phoma sp. is reduced considerably after cross-linking with glutaraldehyde (Hommes et al. 2012).

\section{Oxidation of target compounds}

The results of the screening of the different laccases regarding their capability to oxidize different EOCs generally correspond well to results reported in literature. BPA and DF 
transformation by laccases has been confirmed by several studies (e.g., Uchida et al. 2001; Cabana et al. 2009; Galliker et al. 2010; Marco-Urrea et al. 2010; Tran et al. 2010; Hommes et al. 2012; Hommes et al. 2013), which is consistent with the results of the present study, where high OCRs in the presence of BPA could be measured for all five and in the presence of DF for four of the studied laccases. Furthermore, it has been shown that sulfonamides by laccase alone, i.e., in the absence of redox mediators are only slowly transformed or even not at all (Bialk et al. 2005; Schwarz et al. 2010; Weng et al. 2012). This is in agreement with the present study, where no considerable OCRs could be measured with laccases in the presence of SMX.

Slow degradation of CBZ, IBU, and GFZ by commercial TVL has been previously reported (Tran et al. 2010). However, the authors of this study pointed out that degradation of these compounds might not have been due to laccase activity, since commercially prepared laccase might contain other enzymes and/or redox mediators (Tran et al. 2010). This might explain why no remarkable OCR with TVL in the presence of these three compounds could be measured in our study. Another explanation might be that transformation of these compounds occurred too slowly, and therefore not enough oxygen was consumed over time to detect a noteworthy OCR.

Results of the present study suggest that both BP-2 and BP-4 can be oxidized by some laccases. To the best of our knowledge, there are, to date, no reports on the transformation of these compounds by laccase. Therefore, the occurrence of oxygen consumption by laccases in the presence of these UV absorbers provides first evidence that their degradation is catalyzed by these enzymes.

Resulting OCRs obtained during the screening of the capabilities of the different laccases to oxidize the target substances showed that $\mathrm{pH}$ optima for the different substrates are between 5 and 7 and depend on the substrate as well as on the laccase. This is in agreement with what is reported in literature. It is well known that the $\mathrm{pH}$ optima for laccase activity are highly dependable on the substrate (Kunamneni et al. 2007). For substrates whose oxidation by laccases goes along with an $\mathrm{H}^{+}$dissociation, e.g., phenols or anilines, a bellshaped $\mathrm{pH}$-activity profile with optimal $\mathrm{pH}$ between 5 and 7 is usually reported (Xu et al. 2007).

Two laccases, i.e., CPL and TVL, were selected for the production of a biocatalyst able to oxidize a broad range of EOCs. Selection was based on the results of the screening of the different laccases regarding their ability to oxidize EOCs. The suitability of this approach was demonstrated, since the resulting CPL-TVL-fsNPs were able to transform a broader substrate range than the separate enzymes. Thus, the outlined immobilization method allows for facile formulation and production of biocatalysts tailored for specific applications. One application would be immobilization of laccases for the elimination of specific target pollutants in classical-treated wastewater but other applications in industries, where enzymes are applied can be envisaged like in textile processing, pulp and paper, or food applications.

Acknowledgments The authors thank Wetlands Engineering SPRL and $\mathrm{AB}$ Enzymes $\mathrm{GmbH}$ for the supply of Coriolopsis polyzona and Thielavia laccase, respectively.

The support of the Commission for Technology and Innovation of the Swiss Federal Office for Professional Education and Technology (grant PFNM-NM 9632.1), the Swiss National Science Foundation, 622 National Research Program 66 (project 4066-136686), and the European Commission within the 7th framework program under grant agreement 265946 (MINOTAURUS) and FP7-KBBE-2012-6-311933 (Water4Crops) is gratefully acknowledged.

\section{References}

Bertanza G, Pedrazzani R, Dal Grande M, Papa M, Zambarda V, Montani C, Steimberg N, Mazzoleni G, Di Lorenzo D (2011) Effect of biological and chemical oxidation on the removal of estrogenic compounds (NP and BPA) from wastewater: an integrated assessment procedure. Water Res 45:2473-2484

Bialk HM, Simpson AJ, Pedersen JA (2005) Cross-coupling of sulfonamide antimicrobial agents with model humic constituents. Environ Sci Technol 39(12):4463-4473

Brady D, Jordaan J (2009) Advances in enzyme immobilisation. Biotechnol Lett 31:1639-1650

Cabana H, Alexandre C, Agathos SN, Jones JP (2009) Immobilization of laccase from the white rot fungus Coriolopsis polyzona and use of the immobilized biocatalyst for the continuous elimination of endocrine disrupting chemicals. Bioresource Technol 100:34473458

Cabana H, Ahamed A, Leduc R (2011) Conjugation of laccase from the white rot fungus Trametes versicolor to chitosan and its utilization for the elimination of triclosan. Bioresource Technol 102:16561662

Cirja M, Ivashechkin P, Schäffer A, Corvini PFX (2008) Factors affecting the removal of organic micropollutants from wastewater in conventional treatment plants (CTP) and membrane bioreactors (MBR). Rev Environ Sci Biotechnol 7:61-78

Corvini PFX, Shahgaldian P (2010) LANCE: laccase-nanoparticle conjugates for the elimination of micropollutants (endocrine disrupting chemicals) from wastewater in bioreactors. Rev Environ Sci Biotechnol 9:23-27

Durán N, Rosa MA, D'Annibale A, Gianfreda L (2002) Applications of laccases and tyrosinases (phenoloxidases) immobilized on different supports: a review. Enzyme Microb Technol 31:907-931

Fent K, Zenker A, Rapp M (2010) Widespread occurrence of estrogenic UV-filters in aquatic ecosystems in Switzerland. Environ Pollut 158:1817-1824

Galliker P, Hommes G, Schlosser D, Corvini PFX, Shahgaldian P (2010) Laccase-modified silica nanoparticles efficiently catalyze the transformation of phenolic compounds. J Colloid Interface Sci 349:98-105

Gerencser AA, Neilson A, Choi SW, Edman U, Yadava N, Oh RJ, Ferrick DA, Nicholls DG, Brand MD (2009) Quantitative microplate-based respirometry with correction for oxygen diffusion. Anal Chem 81:6868-6878

Hommes G, Gasser CA, Howald CBC, Goers R, Schlosser D, Shahgaldian P, Corvini PFX (2012) Production of a robust nanobiocatalyst for municipal wastewater treatment. Bioresource Technol 115:8-15 
Hommes G, Gasser CA, Ammann EM, Corvini PFX (2013) Determination of oxidoreductase activity using a high-throughput microplate respiratory measurement. Anal Chem 85:283-291

Hu XK, Hwang HM, Wang P (2009) Oxidation of anthracene by immobilized laccase from Trametes versicolor. Bioresource Technol 100:4963-4968

Klavarioti M, Mantzavinos D, Kassinos D (2009) Removal of residual pharmaceuticals from aqueous systems by advanced oxidation processes. Environ Int 35:402-417

Kunamneni A, Ballesteros A, Plou FJ, Alcalde M (2007) Fungal laccase - a versatile enzyme for biotechnological applications. In: Mendez-Vilas A (ed) Communicating current research and educational topics and trends in applied microbiology. Formatex Research Center, Badajoz, pp 233-245

Kuster M, López de Alda MJ, Hernando MD, Petrovic M, MartínAlonso J, Barceló D (2008) Analysis and occurrence of pharmaceuticals, estrogens, progestogens and polar pesticides in sewage treatment plant effluents, river water, and drinking water in the Llobregat river basin (Barcelona, Spain). J Hydrol 358:112-123

Lapworth DJ, Baran N, Stuart ME, Ward RS (2012) Emerging organic contaminants in groundwater: a review of sources, fate and occurrence. Environ Pollut 163:287-303

Luterek J, Gianfreda L, Wojtaś-Wasilewska M, Cho NS, Rogalski J, Jaszek M, Malarczyk E, Staszczak M, Fink-Boots M, Leonowicz A (1998) Activity of free and immobilized extracellular Cerrena unicolor laccase in water miscible organic solvents. Holzforschung 52:589-595

Majeau JA, Tyagi RD, Brar SK (2010) Laccases for removal of recalcitrant and emerging pollutants. Bioresource Technol 101:23312350

Marco-Urrea E, Pérez-Trujillo M, Cruz-Morató C, Caminal G, Vicent T (2010) Degradation of the drug sodium diclofenac by Trametes versicolor pellets and identification of some intermediates by NMR. J Hazard Mater 176(1-3):836-842

McIlvaine TC (1921) A buffer solution for colorimetric comparison. J Biol Chem 49(1):183-186

Migneault I, Dartiguenave C, Bertrand MJ, Waldron KC (2004) Glutaraldehyde: behavior in aqueous solution, reaction with proteins, and application to enzyme crosslinking. Biotechniques 37(5):790-796, 798-802

Mohidem NA, Mat H (2009) The catalytic activity of laccase immobilized in sol-gel silica. J Appl Sci 9:3141-3145

Pal A, Gin KYH, Lin AYC, Reinhard M (2010) Impacts of emerging organic contaminants on freshwater resources: review of recent occurrences, sources, fate and effects. Sci Total Environ 408:6062-6069

Polizzi KM, Bommarius AS, Broering JM, Chaparro-Riggers JF (2007) Stability of biocatalysts. Curr Opin Chem Biol 11:220-225
Qiu HJ, Xu CX, Huang XR, Ding Y, Qu YB, Gao PJ (2009) Immobilization of laccase on nanoporous gold: comparative studies on the immobilization strategies and the particle size effects. J Phys Chem 113:2521-2525

Rekuć A, Bryjak J, Szymańska K, Jarzębski AB (2009) Laccase immobilization on mesostructured cellular foams affords preparations with ultra-high activity. Process Biochem 44:191-198

Rekuć A, Bryjak J, Szymańska K, Jarzębski AB (2010) Very stable silica-gel-bound laccase biocatalysts for the selective oxidation in continuous systems. Bioresour Technol 101:2076-2083

Schwarz J, Aust MO, Thiele-Bruhn S (2010) Metabolites from fungal laccase-catalysed transformation of sulfonamides. Chemosphere 81(11):1469-1476

Sheldon RA (2007) Enzyme immobilization: the quest for optimum performance. Adv Synth Catal 349:1289-1307

Smith PK, Krohn RI, Hermanson GT, Mallia AK, Gartner FH, Provenzano MD, Fujimoto EK, Goeke NM, Olson BJ, Klenk DC (1985) Measurement of protein using bicinchoninic acid. Anal Biochem 150:76-85

Straathof AJJ, Panke S, Schmid A (2002) The production of fine chemicals by biotransformations. Curr Opin Biotechnol 13:548 556

Tran NH, Urase T, Kusakabe O (2010) Biodegradation characteristics of pharmaceutical substances by whole fungal culture Trametes versicolor and its laccase. J Water Environ Technol 8(2):125-140

Uchida H, Fukuda T, Miyamoto H, Kawabata T, Suzuki M, Uwajima T (2001) Polymerization of bisphenol A by purified laccase from Trametes villosa. Biochem Biophys Res Commun 287(2):355358

Weetall HH (1974) Immobilized enzymes. Anal applications Anal Chem 46(7):602A-615a

Weng SS, Ku KL, Lai HT (2012) The implication of mediators for enhancement of laccase oxidation of sulfonamide antibiotics. Bioresource Technol 113:259-264

Xu F, Damhus T, Danielsen S, Østergaard LH (2007) Catalytic applications of laccase. In: Schmid RD, Urlacher VB (eds) Modern biooxidation, 1st edn. Wiley, Weinheim, pp 43-75

Yang WY, Min DY, Wen SX, Jin L, Rong L, Tetsuo M, Bo C (2006) Immobilization and characterization of laccase from Chinese Rhus vernicifera on modified chitosan. Process Biochem 41(6):13781382

Zhu Y, Kaskel S, Shi J, Wage T, van Pée KH (2007) Immobilization of Trametes versicolor laccase on magnetically separable mesoporous silica spheres. Chem Mater 19:6408-6413

Zimmermann YS, Shahgaldian P, Hommes G, Corvini PFX (2011) Sorption-assisted surface conjugation: a way to stabilize laccase enzyme. Appl Microbiol Biotechnol 92:169-178 